\title{
CARACTERÍSTICAS DA GERMINAÇÃO DE SEMENTES DE 64 ESPÉCIES DE LEGUMINOSAS FLORESTAIS NATIVAS DA AMAZÔNIA, EM CONDIÇÕES DE VIVEIRO.
}

\author{
Fatima Maria de Souza MOREIRA', Francisco Wessen MOREIRA ${ }^{2}$
}

\begin{abstract}
RESUMO - Foram estudados aspectos da germinação de sementes de 64 espécies de leguminosas, nativas da Amazônia, sendo 52 arbóreas, 10 cipós, 1 arbusto e 1 herbácea, oriundas de áreas de terra firme ou periodicamente inundadas. Cinquenta e oito por cento das espécies apresentaram, sem tratamento pré-germinativo, percentagens de germinação maiores que $70 \%$ num período menor que 91 dias. Em 8 espécies de tegumento duro as percentagens de germinação, sem pré-tratamento, encontradas foram menores que $40 \%$. Cinquenta e nove por cento das espécies de áreas inundadas apresentaram uma germinação tipo hipógea enquanto, cinquenta e quatro por cento das espécies de terra firme apresentaram uma germinação epígea. Poliembrionia ocorreu em $22 \%$ das espécies. Sementes com comprimento maior que $3,1 \mathrm{~cm}$ só apresentaram germinaçẫo hipógea enquanto as sementes com comprimento menor ou igual a $1 \mathrm{~cm}$ só apresentaram germinação epígea.
\end{abstract}

Palayras-Chaves: Leguminosas, Amazônia, sementes.

Nursery Germination and Seedling Characteristics of Sixty Four Legume Species Native in the Amazon Forest.

ABSTRACT - Several aspects of seed germination of 64 legume species native from the Amazon forest were studied under nursery conditions. From the total, 52 are trees, 10 are lianes, 1 is a shrub and 1 is a herbaceous plant, all with natural occurence on non-flooded or seasonally flooded sites. Fifty-eight percent of the studied species presented, without pre-treatment, germination above $70 \%$ in periods less than 91 days. Seven species with hard tegument exhibited germination lower than $40 \%$. Fifty nine percent of the species from seasonally flooded sites presented hypogeal germination, while fifty four percent of the species from non-flooded sites presented epigeal germination. Polyembriony occurred in $22 \%$ of the studied species. Seeds with lenght greater than $3.1 \mathrm{~cm}$ presented hipogeal germination only, while seeds with lenght less than or equal $1.0 \mathrm{~cm}$ presented epigeal germination only.

Key Words: Leguminosae, Amazon forest, seeds.

\section{INTRODUÇÃO}

A importância das leguminosas na Amazônia foi ressaltada por HUBER, já em 1910, que a qualificou como "a família mais importante entre todas, na composição das matas Amazônicas e também, sob o ponto de vista de utilidade das suas madeiras". Posteriormente, vários trabalhos confirmaram que esta família predomina na flora amazônica com relação a diversidade de espécies e que está entre as cinco famílias mais abundantes em número de indivíduos (DUCKE 1949; PRANCE et al, 1976). Por outro lado, embora o potencial econômico da maioria das espécies ainda permaneça inexplorado, várias espécies nativas podem ser empregadas em marcenaria de luxo, compensados,

t Departamento de Ciência do Solo, UFLA. Caixa Postal 37, CEP37200-000 Lavras (MG). Bolsista do CNPq.

12 Coordenação de Pesquisas em Ciências Agronômicas, INPA. Alameda Cosme Ferreira, 1756, CEP 69083-000. Manaus (AM). 
celulose e papel, construções em geral, carvão, produtos medicinais e aromáticos, alimentação humana e animal, cercas vivas e produção de gomas, entre outros (LOUREIRO et al., 1979; MOREIRA \& DOBEREINER, 1991).

O conhecimento sobre as características da germinação de espécies florestais representam a base da silvicultura e do manejo sustentado. Características como o tempo de germinação e morfologia inicial de plântulas estão relacionadas com as estratégias de estabelecimento de uma espécie num sítio específico (NG, 1978) sendo, portanto, importantes em estudos que sirvam de base, por exemplo, à regeneração natural de espécies e a sua preservação. Dentre as cêrca de 1221 espécies de leguminosas, que ocorrem na Amazônia (SILVA et al., 1989), poucas foram estudadas quanto a aspectos da germinação de sementes. Os trabalhos realizados até o momento se restringiram a algumas espécies de importância econômica e/ou com disponibilidade de sementes (MACEDO, 1977; ALENCAR \& MAGALHÃES, 1979; COUTINHO \& STRUFFALDI, 1971; LEITE \& RANKIN, 1981; ALENCAR, 1981; VASTANO et al., 1983; BARBOSA et al., 1984; VARELA \& BARBOSA 1986/87: VARELA et al., 1986/87; BARBOSA \& SAMPAIO, 1990). Através de um trabalho de levantamento sobre a capacidade de nodulação (Fixação biológica de $\mathrm{N}_{2}$ ) de leguminosas nativas (MAGALHẪES, 1989; MOREIRA et al., 1992), realizado em vários locais da Amazônia, foi possível a coleta de sementes de várias espécies de leguminosas as quais ainda permaneciam sem informações quanto a aspectos básicos de sua germinação. Informações sobre 10 espécies já foram reportadas em SILVA et al. (1988). Neste trabalho apresentam-se resultados sobre características de sementes e de sua germinação de 64 espécies florestais nativas da Amazônia, pertencentes as três sub-famílias de Leguminosae e oriundas de áreas de terra firme ou periódicamente inundáveis.

\section{MATERIAL E MÉTODOS}

Coleta do material- A maior parte do material foi coletado entre os mêses de fevereiro e maio, em áreas de floresta de terra firme ou periodicamente inundadas, em vários locais da Amazônia. A discriminação do habitat onde cada espécie foi encontrada, assim como o local e data de coleta, se encontram nas Tabelas 1,2 e 3 junto com resultados. Exsicatas das plantas matrizes foram coletadas junto com as sementes e, na maioria dos casos, incorporadas ao herbário do Instituto Nacional de Pesquisas da Amazônia (INPA) onde receberam números de registro que são fornecidos nas Tabelas 1 , 2 e 3 . Foram coletadas 64 espécies, sendo 52 arbóreas, 10 lianas, uma espécie arbustiva e outra herbácea.

Germinação de Sementes e Morfologia inicial de Plantulas (MIP). As sementes foram extraídas diretamente de frutos maduros, colhidos de matrizes, ou, em alguns casos, coletados sob a árvore matriz. A limpeza das sementes foi realizada removendo-se detritos minerais e orgânicos e lavando-as em água corrente. O tamanho das sementes de cada espécie foi medido através de seu comprimento tomado ao longo do eixo maior. Logo após o retorno das excursóes que duravam em média 10 dias, as sementes foram colocadas para germinar, em caixas 
contendo areia lavada como substrato, a profundidade de aproximadamente $0,5 \mathrm{~cm}$. Estas caixas estavam situadas num galpão coberto por telhas de amianto sem paredes laterais. Dependendo da disponibilidade de sementes em cada espécie, foram utilizadas duas, três ou quatro repetições de 25 sementes cada. Em poucos casos o tamanho da amostra ou das repetições foi menor que 25 sementes. Isto ocorreu no caso de árvores muito altas e/ou cujos frutos são bastante predados como foi o caso de Lecointea amazonica. A germinação de seis espécies que apresentaram tegumento duro foi verificada com e sem tratamento prégerminativo com $\mathrm{H}_{2} \mathrm{SO}_{4}$ concentrado ou água quente. Essas espécies e seus respectivos tratamentos foram: Peltogyne paniculata (15 min. $\mathrm{H}_{2} \mathrm{SO}_{4}$ conc.); Parkia discolor (10 min. $\mathrm{H}_{2} \mathrm{SO}_{4}$ conc.); Parkia oppositifolia (25 min. $\mathrm{H}_{2} \mathrm{SO}_{4}$ conc.); Pithecellobium multiflorum. (10 min. $\mathrm{H}_{2} \mathrm{SO}_{4}$ conc.); Ormosia excelsa (30 min. em água quente); Ormosia macrocalyx (30 min. em água quente). A temperatura ambiente média durante os experimentos foi de $28 \pm 3^{\circ} \mathrm{c}$ e o regime de luz da região de Manaus pode ser verificado em RIBEIRO et al. (1982). Através de irrigação diâria o substrato foi mantido úmido. O critério usado para a determinação de sementes germinadas foi a emergência do caulículo sendo o acompanhamento feito diariamente até que a taxa diária de germinação se mantivesse em zero por pelo menos uma semana. Plântulas foram coletados em diversas fases da germinação, armazenadas em álcool $(70 \%)$ e posteriormente fotografadas para registro de aspectos morfológicos. Neste trabalho considerou-se, principalmente, as grandes divisões epígea e hipógea, porém, sempre que possível procuramos identificar a morfologia inicial de plântulas (M.I.P.) com base nas subdivisões fanerocotilar e criptocotilar, com cotiledones carnosos ou foliáceos sugeridas por DUKE (1965), NG (1978) e HLADIK \& MIQUEL (1990).

\section{DISCUSSÃO}

\section{Tamanho das Sementes}

O tamanho das sementes das leguminosas nativas da Amazônia também é bastante variável. Neste trabalho foram encontradas espécies com sementes de 0,3 $\mathrm{cm}$ (Mimosa polystachya) até $10 \mathrm{~cm}$ (Mora paraensis) de comprimento. A maior frequência encontrada foi para a classe de sementes entre 1,1 e $2,0 \mathrm{~cm}$ representando $44 \%$ do total de espécies . Nas Caesalpinioideae não ocorreram espécies com sementes de comprimento menor ou igual a $1 \mathrm{~cm} \mathrm{e} 36 \%$ das espécies (5) tinham comprimento da semente maior que $3,1 \mathrm{~cm}$ (Tab. 1), Nas Mimosoideae só uma espécie (Pentaclethra macroloba), representando $4 \%$ do total, teve comprimento maior que 3,1 (Tab. 2). Nas Papilionoideae a ocorrência de 5 espécies com sementes de comprimento maior que $3,1 \mathrm{~cm}(25 \%)$ foi devido principalmente às espécies da Tribo Swartzieae reconhecida como de transição entre as Caesalpinioideae e as Papilionoideae (Tab. 3). Excetuando sementes de comprimento maior que $5 \mathrm{~cm}$, que não foram encontradas em áreas de terra firme, todas as demais classes de semente foram encontradas tanto em áreas de terra firme como em áreas periodicamente inundadas. 
Tabela 1. Características de sementes e de sua germinação de Leguminosas nativas da Amazổnia. 1. Caesalpinioideae

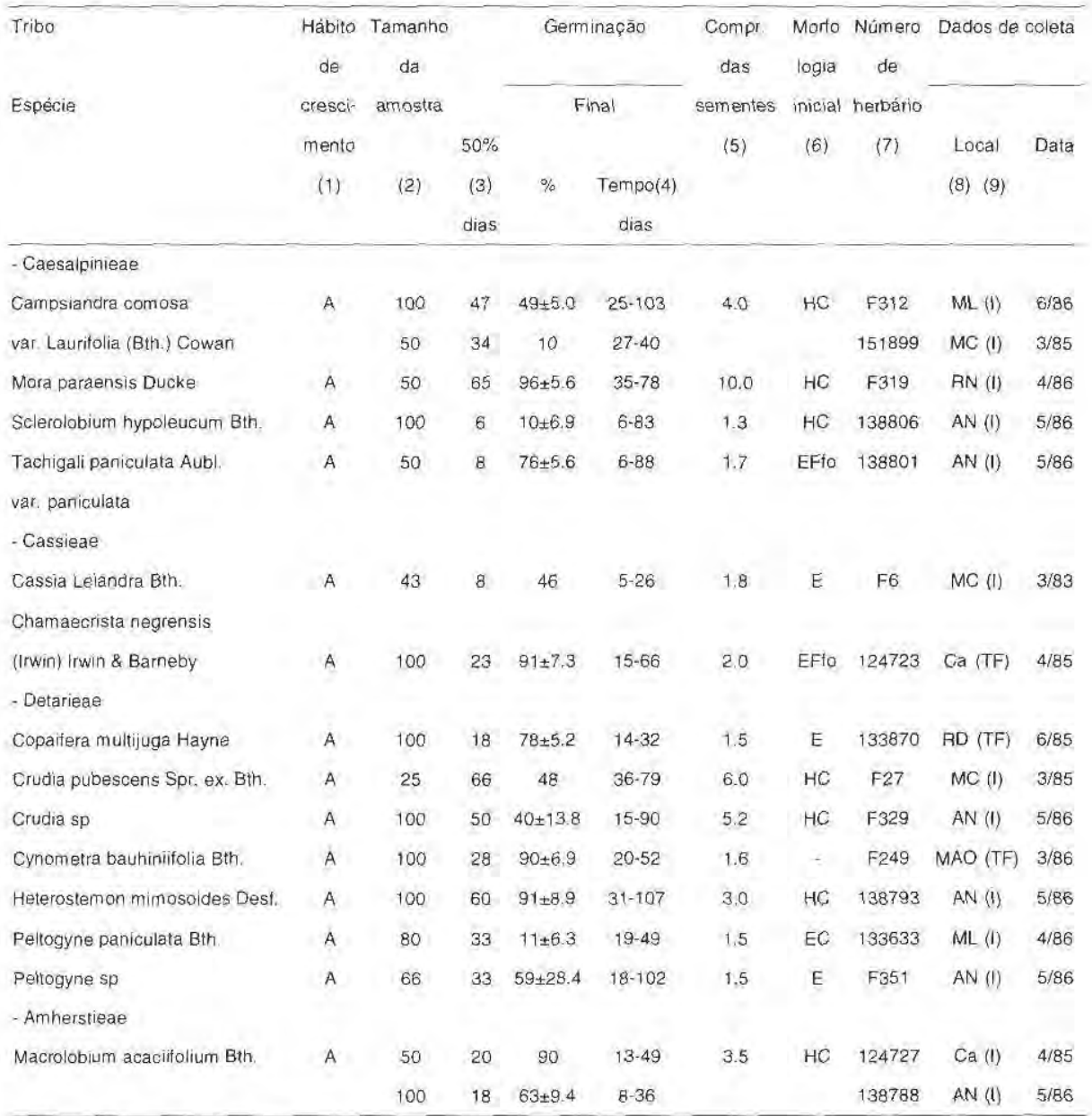

(1) $A=$ Árvore; $L=$ Liana; he= herva.

(2) Número de sementes testadas.

(3) Tempo para germinação de $50 \%$ das sementes viáveis.

(4) Dias após a semeadura nos quais a $1^{\circ} \mathrm{e}$ última plảntula apareceram.

(5) Medido ao longo do eixo maior da semente.

(6) $\mathrm{E}=$ epigea: $\mathrm{H}=$ hipogea; $\mathrm{F}=$ fanerocotilar; $\mathrm{C}=$ criptocotilar; $\mathrm{ca}=$ cotiledones camosos; $\mathrm{fo}=$ cotiledones foliaceos .

(7) Nứmero de herbário do INPA (Instituto Nacional de Pesqùisas da Amazònia) ou da coleçăo do autor mantida no herbário (F)

(8) $\mathrm{MAO}=$ Cidade de Manaus; $\mathrm{MC}=$ Municipio de Manacapuru/Distrito do Caviana; $\mathrm{ML}=$ Municipio de Manacapuru/Lago do Calado; $\mathrm{Ca}=\mathrm{Acre} ; \mathrm{RN}=$ Rio Negro próximo a Manaus; $\mathrm{RS}=$ Rio Solimóes próximo a Manaus; AN Arquipélago de Anavithanas; $\mathrm{RD}=$ Reserva Florestal Ducke (próximo a Manaus).

(9) $(\mathrm{TF})=$ Terra firme

(I) = Área sujeita a inundaçòes periódicas 
Tabela 2. Características de sementes e sua germiação de Leguminosas nativas da Amazônia. II. Mimosoideae

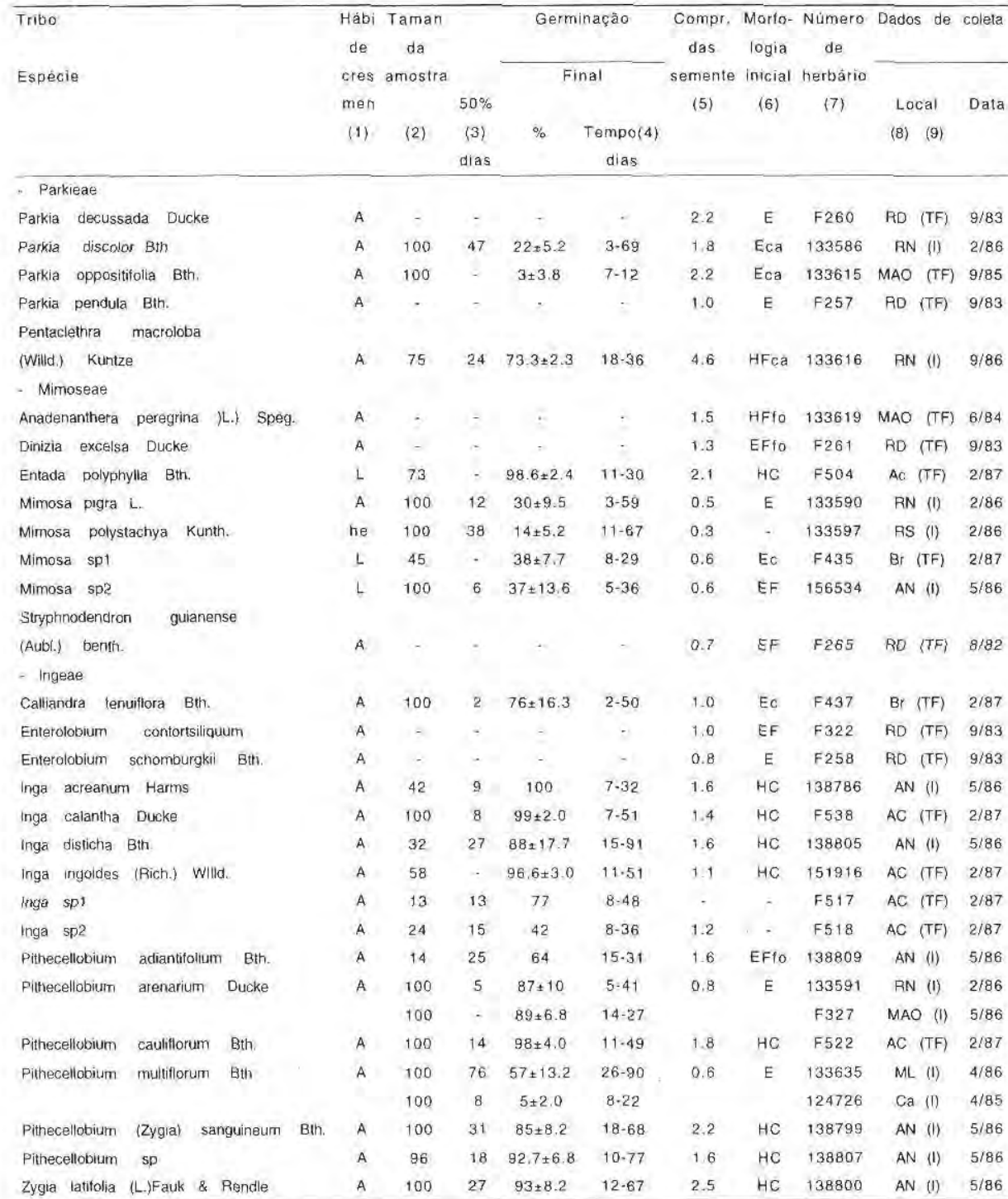

(1) $A=$ Arvare: $L=$ Liana; hes herva.

(2) Número de sementes testadas.

(3) Tempo para germinaçảo de $50 \%$ das sementes viaveis.

(4) Dias após a semeacuura nos quais a $7^{\text {i2 }}$ e úitima plântula apareceram-

(5) Medido ao longo do eixo maior da semente.

(6) $\mathrm{E}=$ epigea; $\mathrm{H}=$ hipogea; $\mathrm{F}=$ fanerocotilar; $\mathrm{C}=$ criptocotilar; $\mathrm{ca}=$ cotiledones tarnosos; lo= coliledones foliaceos.

(7) Nümero de herbário do INPA (Instituto Nacional de Pesquisas da Amazônia) ou da coleção do autor mantida no herbario (F).

(8) $\mathrm{MAO}=$ Cidade de Manaus: $\mathrm{MC}=$ Municipio de Manacapuru/Distrito do Caviana; $\mathrm{ML}=$ Municipio de Manacapuru/Lago do Calado; $\mathrm{Ca}=$ Acre; $\mathrm{RN}=$ Fio Negro próximo a Manaus; $\mathrm{AS}=$ Rio Solimōes próximo a Manaus: AN Arquipélago de Anavilhanas: $\mathrm{AD}=$ Reserva Florestal Ducke (próximo a Manaus).

(9) $(T F)=$ Terra firme

(I) = Area sujeita a inundaçōes periódicas 
Tabela 3. Características de sementes e sua germinação de Leguminosas nativas da Amazônia. III. Papilionoideae.

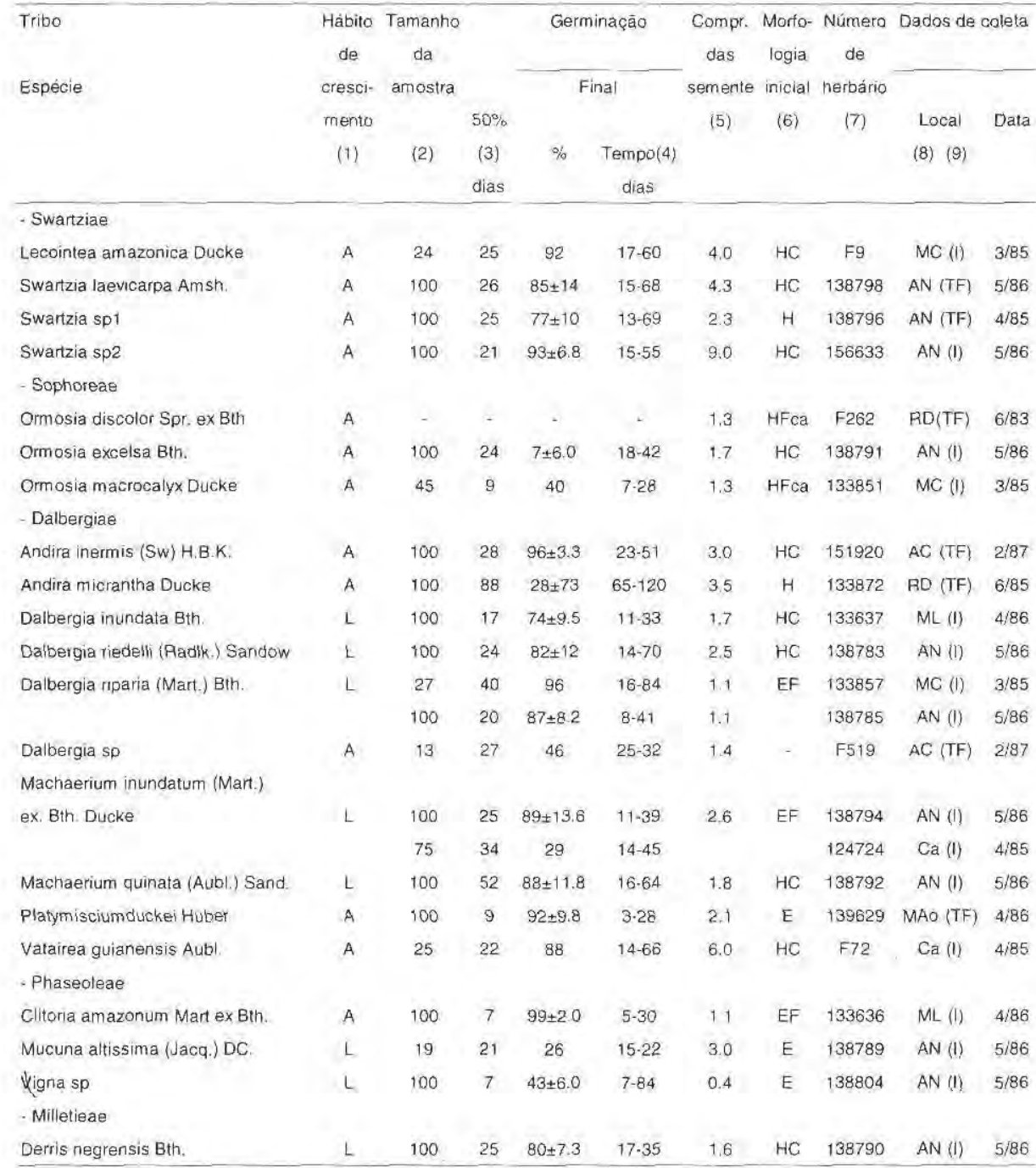

(1) $A=$ Árvore; $L=$ Liana; he= herva.

(2) Numero de sementes testadas.

(3) Tempo para germinaçào de $50 \%$ das sementes viàveis.

(4) Dias após a semeadura nos quais a $1^{\circ} e$ ứltima plântula apareceram

(5) Medido ao longo do eixo maior da semente.

(6) $\mathrm{E}=$ epigea; $\mathrm{H}$ =hipogea: $\mathrm{F}=$ fanerocotilar; $\mathrm{C}=$ criptocotilar; $\mathrm{ca}=$ cotiledones camosos; fo= cotiledones foliaceos.

(7) Número de herbário do INPA (Instituto Nacional de Pesquisas da Amazỏnia) ou da coleçâo do autor mantida no herbario (F).

(8) $\mathrm{MAO}=$ Cidade de Manaus: $\mathrm{MC}=$ Municipio de Manacapuru/Distrito do Caviana: $\mathrm{ML}=$ Municipio de Manacapuru/Lago do Calado; $\mathrm{Ca}=\mathrm{Acre} ; \mathrm{RN}=\mathrm{Alo}$ Negro próximo a Manaus; $\mathrm{RS}=$ Rio Solimóes próximo a Manaus; AN Arquipélago de Anavilhanas; $R D=$ Reserva Florestal Ducke (proximo a Manaus).

(9) $(\mathrm{TF})=$ Terra firme

(I) = Área sujeita a inundaçōes periódicas 


\section{Germinação}

A percentagem de germinação das espécies estudadas variou de 3 até $100 \%$ apresentano pouca variação nesta amplitude entre as sub-famílias. Entretanto as médias de porcentagem de germinação foram de: 59,$6 ; 65,3$ e 70,7\% para Caesalpinioideae, Mimosoideae e Papilionoideae respectivamente. Cinquenta e oito porcento do total de espécies estudadas apresentaram percentagens de germinação maior ou igual a $70 \%$ num periodo menor que 98 dias e portanto, podem ser consideradas de germinação rápida de acordo com a definição de NG (1978). Em florestas da Malásia NG (1978) encontrou uma frequência um pouco maior $(65 \%)$ de espécies com germinação rápida. Nas seis espécies seguintes foi testada a germinação de sementes com diferentes procedências (matriz ou local), A percentagem de germinação variou bastante para as espécies Campsiandra comosa (10-49\%), Macrolobium acacifolium (63-90\%), Pithecellobium multiflorum (5-57\%) e Machaerium inundatum (29-89\%). Para as espécies: Pithecelobium arenarium (87-89\%) e Dalbergia riparia $(87-96 \%)$ variou pouco. Com exceção da Pithecellobium multiflorum, todas as espécies tiveram as diferentes procedências de sementes coletadas em épocas (meses) diferentes e, portanto, com possibilidade de estarem em pontos diferentes de maturação fisiológica o que, possívelmente, influenciou a percentagem de germinação. Algumas espécies estudadas neste trabalho já haviam sido observadas em outros trabalhos. Para todas a percentagem de germinação encontrada teve pouca variação. São elas: Tachigalia paniculata (72-76\%) (SILVA et al., 1988), Chamaecrista negrensis (7791\%) (SILVA et al., 1988), Copaífera multijuga (78-88\%) (ALENCAR, 1981), Macrolobium acaciifolium (6378-90\%) (SILVA et al., 1988), Crudia pubescens (43-48\%) (SILVA et al., 1988), Swartzia laevicarpa (85-96\%) (MOREIRA et al,, submetido), e Vatairea guianensis (88-91\%) (SILVA et $a l ., 1988)$. As frequências de espécies com germinação superior a $70 \% \mathrm{em}$ áreas de terra firme e periodicamente inundadas foram repectivamente $76 \% \mathrm{e}$ $51 \%$.O tempo para germinação de $50 \%$ das sementes viáveis variou de 2 a 88 dias. Estes tempos médios foram de 32, 21 e $26 \%$ respectivamente para as subfamílias Caesalpinioideae, Mimosoideae e Papilionoideae.

\section{Tegumento duro}

Espécies de tegumento duro ocorreram nas 3 sub-famílias. Das 56 espécies cuja germinação foi estudada oito apresentaram tegumento duro: Peltogyne paniculata, Parkia discolor, P. oppositifolia, Pithecellobium multiflorum, Ormosia excelsa, $O$. macrocalyx, Mucuna altissima e Andira micrantha. Estas espécies representaram $50 \%$ das espécies que apresentaram percentagem de germinação menor que $40 \%$. O tratamento com $\mathrm{H}_{2} \mathrm{SO}_{4}$ (conc.) ou água quente aumentou a percentagem de germinação nas seis primeiras espécies de: $11,22,3,7,7$ e $40 \%$, para: 79,82 , $96,65,30$ e $58 \%$ respectivamente. 
VARELA et al. (1986/87) citam que o tegumento duro pode conferir viabilidade por longos períodos. Após tratamento com $\mathrm{H}_{2} \mathrm{SO}_{4}, 96 \%$ das sementes de Parkia decussata germinaram 3 meses após coleta e BARBOSA et al. (1984) demonstraram que $68 \%$ das sementes de Parkia pendula germinaram 35 meses após coleta. Sem tratamento as taxas de germinação dessas espécies foram $1 \%$ e 0 , respectivamente. Sementes de Parkia oppositifolia germinaram 7 anos após a coleta (F.M.S. MOREIRA, dados não publicados).

\section{Morfologia Inicial de Plântulas (M.I.P.)}

Tanto espécies hipógeas como espécies epígeas ocorreram nas 3 subfamílias (Tabs. 1, 2 e 3) porém, houve predominância do tipo hipógeo( $70 \%$ ) nas Papilionoideae o que condiz com a condição avancada desta sub-família, pois segundo EAMES (1961) o tipo hipógeo é um caráter claramente avançado. Nas Caesalpinioideae e Mimosoideae as frequências de germinação hipógea foram respectivamente: 54 e $38 \%$. Só um tipo morfológico de plântula ocorreu nas tribos: Cassieae (epígeo), Swartzieae (hipógeo), Sophoreae (hipógeo) e Phaseoleae (epígeo). Nas outras tribos estudadas (Caesalpinieae, Detarieae, Dalbergieae, Parkieae, Mimosaceae e Ingeae) ocorreram tanto espécies epígeas como hipógeas. Esta heterogeneidade ocorreu também nos gêneros: Dalbergia, Machaerium e Pithecellobium. A M.I.P. de leguminosas tropicais foi estudada por outros autores em florestas do Panamá e Colômbia (DUKE 1969), da Malásía (NG, 1978) e da África (HLADIK \& MIGUEL, 1990). DUKE (1969) comenta a existência de espécies hipógeas e epígeas em vários gêneros. Dentre eles citamos: Bauhinia, Caesalpinia, Ormosia, Phaseolus, Phithecellobium e Pterocarpus. Os resultados deste trabalho sobre M.I.P. coincidem com os de DUKE (1969) para espécies dos gêneros: Inga, Pithecellobium, Pentaclethra, Mora e Swartzia; de NG (1978) para: Crudia, Ormosia e Parkia e de HLADIK \& MIGUEL (1990) para Crudia, Entada, Parkia e Pentaclethra. Ao contrário dos resultados obtidos por HLADIK \& MIQUEL (1990) para espécies africanas de Swartzia, este e outros trabalhos (MACEDO, 1977; SILVA et al., 1988; MOREIRA et al., submetido) encontraram somente espécies hipogeas criptocotilares neste gênero na Amazônia. DUKE (1969) reportou uma espécie criptocotilar (provavelmente hipógea) neste gênero. Os tipos "hipógeo fanerocotilar com cotiledones fotossintéticos" "epígeo criptocotilar" representam tipos com desvantagem em relação aos outros pois, fazer fotossíntese ao nível do chão elimina a possibilidade de competição por luz, e, elevar os cotilédones para mantê-los escondidos da luz é claramente um desperdício de energia. Por isso, estes dois tipos são geralmente menos frequentes (NG, 1978; HLADIK \& MIGUEL, 1990). Epígeas criptocotilares foram também pouco frequentes entre as espécies observadas. Só foi constatado este tipo em Peltogyne paniculata e Calliandra tenuiflora. Peltogyne prancei cuja germinação foi estudada por SILVA et al. (1988) também tem este tipo de M.I.P.. As hipógeas fanerocotilares 
com cotiledones fotossintéticos foram de difícil identificação. Na maioria das vezes os cotiledones não ficavam expostos completamente (por exemplo: Ormosia spp e Inga spp) por isso foram considerados criptocotilares. Eṃ outros casos os cotiledones carnosos ficavam verdes indicando uma função dupla de fotossíntese e armazenamento como o observado por NG (1978). HLADIK \& MIQUEL (1990) encontraram predominância do tipo epígeo não só entre 210 espécies nativas, pertencentes a 48 famílias botânicas mas, também, na família Leguminosae (21 das 30 espécies estudadas). Outros autores também encontraram o tipo epígeo fanerocotilar com cotiledones fotossintéticos como o mais abundante na flora tropical de florestas do Gabon (MIQUEL, 1987), da Malásia (NG, 1978), do Panamá (GARWOOD, 1983) e de Guadalupe (ROUSTEAU, 1983). Na família Dipterocarpaceae, por exemplo, que é predominante nas florestas da Malásia, também predomina o tipo epígeo. Os resultados aqui obtidos coincidem com estas observações para as espécies de terra firme na Amazônia aonde predominou o tipo epígeo $(54,5 \%)$. Nas florestas inundadas, no entanto, o tipo hipógeo predominou ocorrendo em $59,5 \%$ das espécies. Estas frequências porém, podem não ser representativas das Leguminosae na Amazônia, pois, apenas 5\% (64 das 1221) das espécies foram analisadas neste trabalho. Por outro lado, a maior parte das espécies foi coletada no período de fevereiro a maio, assim, os resultados encontrados podem refletir apenas a tendência deste período.

\section{Poliembrionia}

A poliembrioinia, definida como a ocorrência de mais de um embrião dentro da semente é um caráter importante, tanto em termos ecológicos como econômicos, pois pode representar uma fonte de material genético estável (TOLEDO \& MARCOS FILHO, 1977). Neste trabalho, poliembrionia foi observada nas 3 sub-famílias em espécies dos gêneros: Mora (F319); Cynometra (F249); Peltogyne (133633); Macrolobium (138788); Crudia (F329); Swartzia (156533, 138796); Dalbergia (138785); Pentaclethra (133616), Inga (F538), Pithecellobium (F522, 138807); Zygia (138800) e ainda na espécie Anadenanthera peregrina (133619). O fenômeno teve uma frequência razoável, ocorrendo em $22 \%$ das espécies estudadas. Nas sub-famílias sua frequência foi respectivamente 31 , 25 e $14 \%$ para Caesalpinioideae, Mimosoideae e Papilionoideae.

\section{Relações Ecológicas}

Em sementes com comprimento menor que I cm só ocorreu o tipo epígeo. Nas sementes com comprimento entre 1,1 e $3,0 \mathrm{~cm}$ predominou o tipo hipógeo enquanto, as sementes com comprimento maior que $3,1 \mathrm{~cm}$ só apresentaram o tipo hipógeo (Fig. 1). A relação entre tamanho de semente e M.I.P. pode estar relacionada com a dispersão das sementes. Sementes pequenas podem ser dispersas a maiores distâncias, tendo assim a possibilidade de colonizar locais com maior incidência de luz, onde a germinação epígea fanerocotilar 
é mais vantajosa. Sementes grandes são geralmente dispersas a menores distâncias, ficando na maioria das vêzes sob a copa da árvore matriz com limitação de luz. Neste caso, a germinação hipógea associada a sementes grandes permite disponibilidade de maior quantidade de reservas.

$\mathrm{Na}$ classe de tamanho de sementes entre 1,1 e 2,0 cm, com maior frequência de espécies, ocorreram $50 \%$ (18) das espécies (35) que apresentaram germinação maior que $70 \%$, e também ocorreu a maior parte das sementes com tegumento duro. A frequência dos tipos epígeo e hipógeo, nesta classe, foi, respectivamente, 48 e $52 \%$. A frequência de espécies com germinação maior que $70 \%$ nas sementes com comprimento menor ou igual a $1 \mathrm{~cm}$ foi baixa (Fig. 2). Com exceção desta e da classe de crescimento de 3,1 a $4,0 \mathrm{~cm}$, em todas as outras classes foi maior a frequência das espécies com taxa de germinação maior que $70 \%$.

Das sementes que apresentaram germinação maior que $70 \%, 11$ (19\%) eram epígeas e $23(40 \%)$ eram hipógeas representando setenta e dois por cento das espécies hipógeas e $44 \%$ das espécies epígeas (Fig. 3).

\section{Considerações Finais}

Nas 64 espécies abrangidas por este estudo, que representam cêrca de $5 \%$ das 1221 espécies de leguminosas nativas da Amazônia, encontrou-se ampla variação de tamanho de sementes, porcentagens de germinação e tipos morfológicos de plântulas, assim como uma frequência significativa de espécies com sementes poliembrionicas e espécies de tegumento duro. Apesar do número relativamente baixo de espécies analisadas verificou-se uma frequência diferenciada destas

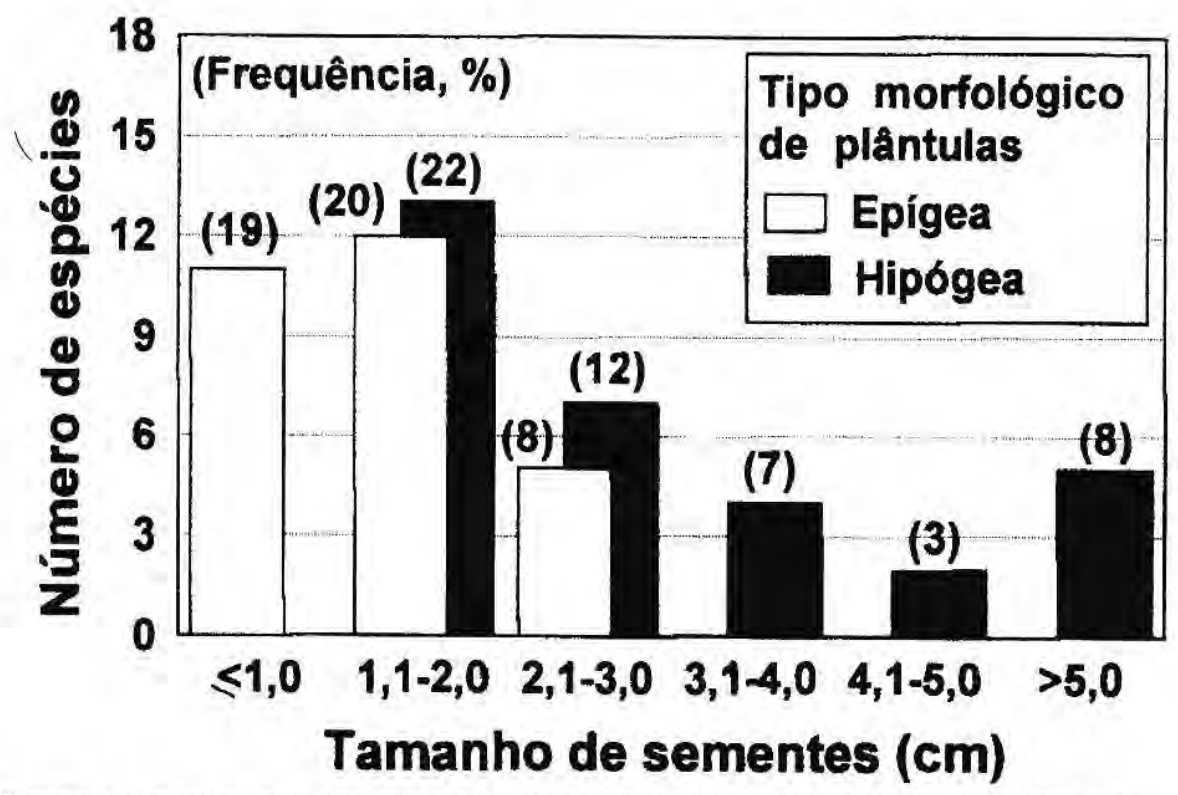

Figura 1. Frequência do tipo mofológico de plântulas por classe de tamanho de sementes. 


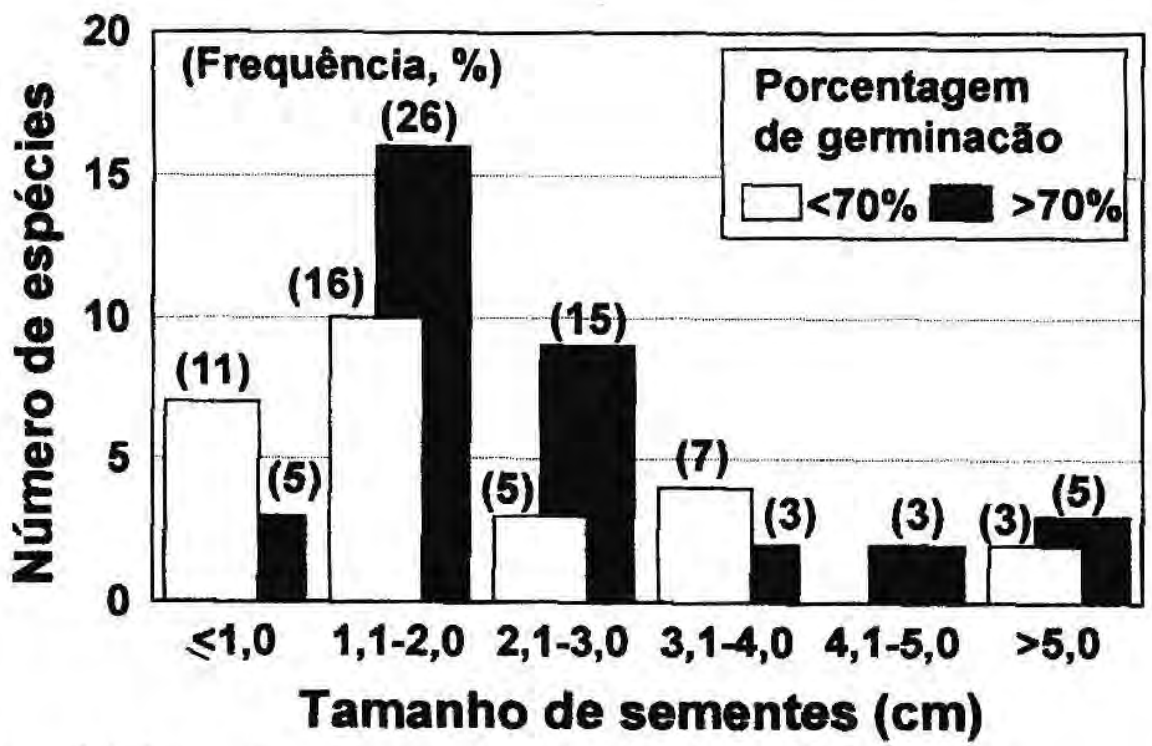

Figura 2. Relação entre porcentagem de germinação e tamanho de sementes.

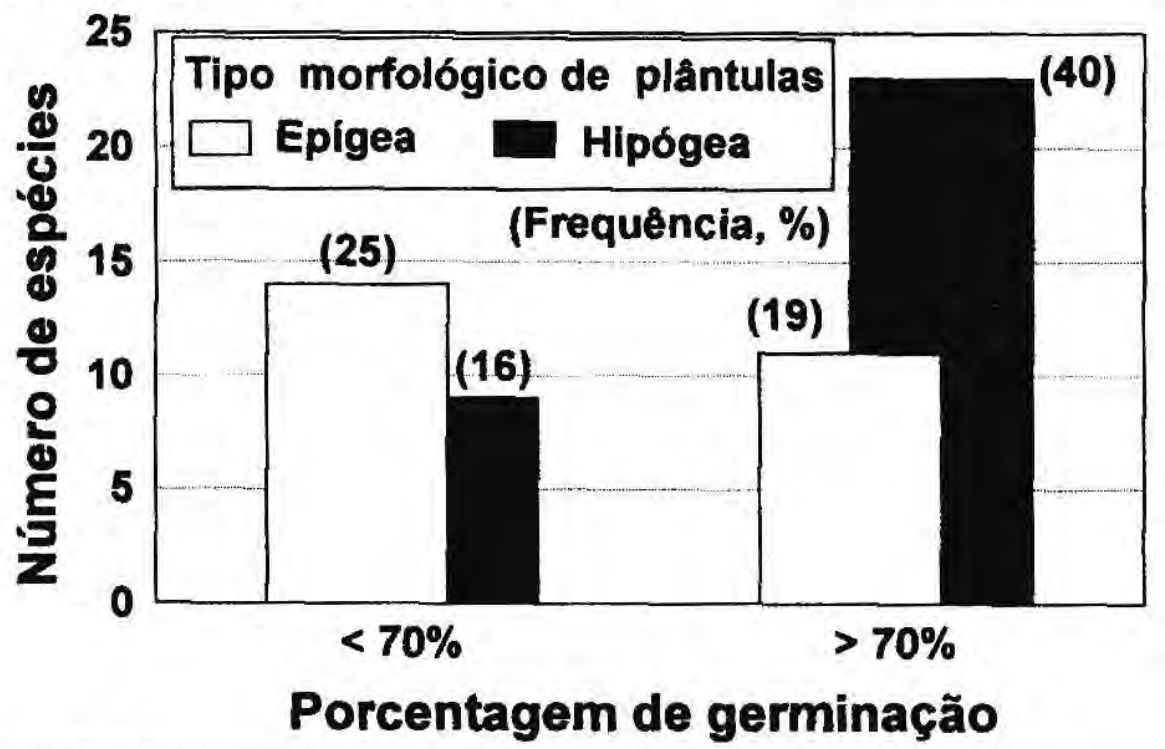

Figura 3. Relação entre porcentagem de germinação e tipo morfológico de plântulas.

características nas diferentes sub-famílias.

Nas Papilionoideae encontrou-se a maior taxa de germinação média $(70,7 \%)$, a maior frequência de germinação hipógea (70\%) e, a menor incidência de sementes poliembriônicas (3). Nas Mimosoideae ocorreu a maior frequência de espécies epígeas (62\%), a maior incidência de espécies com sementes poliembriônicas (6), a taxa média de germinação foi de $65,3 \%$ e, não foram encontradas espécies com sementes de comprimento maior que $5 \mathrm{~cm}$. Nas Caesalpinioideae ocorreu a menor taxa de germinação média 
$(59,6 \%)$, ocorreram cinco espécies com sementes poliembriônicas e, não foram encontradas espécies com sementes de comprimento menor ou igual a $1 \mathrm{~cm}$.

\section{AGRADECIMENTOS}

Os autores agradecem à FINEP e ao $\mathrm{C} \ \mathrm{Pq}$ pelo suporte financeiro.

\section{Bibliografia citada}

ALENCAR, J.C. 1981. Estudos silviculturais de uma população natural de Copaifera multijuga Hayne Leguminosae na Amazônia Central. 1. Germinação. Acta Amazonica, II(1): 3-11.

ALENCAR, J.C; MAGALHÃES, L.M.S. 1979. Poder germinativo de sementes de doze espécies florestais da região de Manaus. 1. Acta Amazonica, 9(3): 411-418.

BARBOSA, A. P. ; VASTANO Jr., B.; VARELA, V.P. 1984. Tratamentos pré-germinativos de sementes de espécies florestais amazônicas. II. Visgueiro (Parkia pendula Benth. Leguminosae Mimosoideae). Acta Amazonica, 14 ( ) : 280-288.

BARBOST, A.P. ; SAMPAIO, P. T.B. 1990. Efeito da profundidade de semeadura e posição da semente na germinação e formação da haste das mudas de cedrorana (Cedrelinga catenaeformis Ducke). Acta Amazonica, 20( ): 3-10.

COUTINHO, L.M.; STRUFFALDI, Y. 1971. Observações sobre a germinação das sementes e o crescimento das plântulas de uma leguminosa da Mata Amazônica de Igapó (Parkia auriculata Spruce ex Mss). Fiton, 28(2):149-159.

DUCKE, A. 1949. Notas sobre a flora neotrópica. II. As leguminosas da Amazônia Brasileira, Belém, IAN, 248p. (IAN. Boletim Técnico, 18).

DUKE, J.A. 1965. Keys of identification of seedlings of some prominent woody species in eight forest types in Puerto Rico. Annals of the Missouri Botanical Garden, 52:314-350.

DUKE, J.A. 1969. On tropical tree seedlings. I.
Seeds, seedlings, systems and systematics. Annals of Missouri Botanical Garden, 56(2): 125-161.

EAMES, A.J. 1962. Morphology of the Angiosperms. Mc Graw-Hill. Book Co., Inc. New York, 1961, 518 p.

GARWOOD, N.C. 1983. Seed germination in a seasonal tropical forest in Panama. A community study. Ecological Monographs, 53: 59-84.

HLADIK, A.; MIQUEL, S. 1990. Seedling types and plant establishment in an African rain forest. In: BAWA, K.S.; MADDLEY, M. (eds). Reprodutive ecology of tropical forest plants. Man and Biosphere. (Series):7. Unesco.

HUBER, J. 1910. Matas e madeiras amazônicas. Bol. Museu Paraense Emílio Goeldi Hist. Nat. Ethnogr., 6:91-225.

LEITE, A.M.C; RANKIN, J.M. 1981. Ecologia de Pithecellobium racemosum. Ducke. Acta Amazonica, 11(2): 309-318.

LOUREIRO, A.A.; SILVA, M.F; ALENCAR, J.C. 1979. Essências madeireiras da Amazônia. Vols. I e II, INPA/Sup. Zona Franca de Manaus/SUFRAMA.

MACEDO, M. 1977. Dispersão de plantas lenhosas de uma Campina Amazônica. Acta Amazonica, 7(1):1-69.

MAGALHÃES, F.M.M. 1989. Relatório técnico final do projeto: Levantamento da capacidade de nodulação elou fixação de nitrogênio de espécies florestais da região amazônica. Convênio INPA/FINEP/ CODEAMA. ref. no. 54.84.0294.00, 54p.

MIQUEL, S. 1987. Morphologie fonctionnelle de plantules d'espéces forestières du Gabon. Bulletin du Muséum National d' Histoire naturelle. Paris, 4 éme série, section $\mathrm{B}$. Adansonia, a: 101-21.

MOREIRA, F.M.S.; DOBEREINER, J. 1991. Alternatives for maintenance and recovery of soil fertility after deforestation of Amazon forest. Study week: man and his environment. Pontificia Academia Scientiarum, Vaticano City, 42p.

MOREIRA, F.W.; MOREIRA, F.M.S.; SILVA, M.F. 1994. Germinação, crescimento 
$(59,6 \%)$, ocorreram cinco espécies com sementes poliembriônicas e, não foram encontradas espécies com sementes de comprimento menor ou igual a $1 \mathrm{~cm}$.

\section{AGRADECIMENTOS}

Os autores agradecem à FINEP e ao CN'Pq pelo suporte financeiro.

\section{Bibliografia citada}

ALENCAR, J.C. 1981. Estudos silviculturais de uma população natural de Copaifera multijuga Hayne Leguminosae na Amazônia Central. 1. Germinação, Acta Amazonica, 11(1): 3-11.

ALENCAR, J.C; MAGALHÃES, L.M.S. 1979. Poder germinativo de sementes de doze espécies florestais da região de Manaus. I. Acta Amazonica, 9(3): 411-418.

BARBOSA, A. P. ; VASTANO Jr. , B.; VARELA, V.P. 1984. Tratamentos pré-germinativos de sementes de espécies florestais amazônicas. II. Visgueiro (Parkia pendula Benth. Leguminosae Mimosoideae). Acta Amazonica, 14 ( ) : 280-288.

BARBOS A, A.P. ; SAMPAIO, P. T.B. 1990. Efeito da profundidade de semeadura e posição da semente na germinação e formação da haste das mudas de cedrorana (Cedrelinga catenaeformis Ducke). Acta Amazonica, 20( ): 3-10.

COUTINHO, L.M.; STRUFFALDI, Y. 1971. Observações sobre a germinação das sementes e o crescimento das plântulas de uma leguminosa da Mata Amazônica de Igapó (Parkia auriculata Spruce ex Mss). Fiton, 28(2):149-159.

DUCKE, A, 1949. Notas sobre a flora neotrópica. II. As leguminosas da Amazônia Brasileira, Belém, IAN, 248p. (IAN. Boletim Técnico, 18).

DUKE, J.A. 1965, Keys of identification of seedlings of some prominent woody species in eight forest types in Puerto Rico. Annals of the Missouri Botanical Garden, 52:314-350.

DUKE, J.A. 1969. On tropical tree seedlings. I.
Seeds, seedlings, systems and systematics. Annals of Missouri Botanical Garden, 56(2): 125-161.

EAMES, A.J. 1962. Morphology of the Angiosperms. Mc Graw-Hill. Book Co., Inc. New York, 1961, 518 p.

GARWOOD, N.C. 1983. Seed germination in a seasonal tropical forest in Panama. A community study. Ecological Monographs, 53: 59-84.

HLADIK, A.; MIQUEL, S. 1990. Seedling types and plant establishment in an African rain forest. In: BAWA, K.S.; MADDLEY, M. (eds). Reprodutive ecology of tropical forest plants. Man and Biosphere. (Series):7. Unesco.

HUBER, J. 1910. Matas e madeiras amazônicas. Bol. Museu Paraense Emilio Goeldi Hist. Nat. Ethnogr, 6:91-225.

LEITE, A.M.C.; RANKIN, J.M. 1981. Ecologia de Pithecellobium racemosum. Ducke. Acta Amazonica, 11(2): 309-318.

LOUREIRO, A.A.; SILVA, M.F; ALENCAR, J.C. 1979. Essências madeireiras da Amazônia. Vols. I e II, INPA/Sup. Zona Franca de Manaus/SUFRAMA.

MACEDO, M. 1977. Dispersão de plantas lenhosas de uma Campina Amazônica. Acta Amazonica, 7(1):1-69.

MAGALHĀES, F.M.M. 1989. Relatório técnico final do projeto: Levantamento da capacidade de nodulação elou fixação de nitrogênio de espécies florestais da região amazônica, Convênio INPA/FINEP/ CODEAMA. ref. no. $54.84 .0294 .00,54 \mathrm{p}$.

MIQUEL, S. 1987. Morphologie fonctionnelle de plantules d'espéces forestières du Gabon. Bulletin du Muséum National d' Histoire naturelle. Paris, 4 éme série, section B. Adansonia, a: 101-21.

MOREIRA, F.M.S.; DOBEREINER, J. 1991. Alternatives for maintenance and recovery of soil fertility after deforestation of Amazon torest. Study week: man and his environment. Pontificia Academia Scientiarum, Vaticano City, $42 \mathrm{p}$.

MOREIRA, F.W.; MOREIRA, F.M.S.; SILVA, M.F. 1994. Germinação, crescimento 
inicial e nodulação em viveiro de saboarana (Swartzia laevicarpa Amshoff). Submetido a Acta Amazonica.

NG, F.S.P. 1978. Strategies of establishment in Malayan forest trees. $\mathrm{n}$ : P. B. TOMLINSONAND, P. B.; ZIMMERMANN, M.H. (eds.). Tropical Tress as Living Systems. Cambridge University Press, Cambridge, p. 129-162.

PRANCE, G.T.; RODRIGUES, W.A.; SILVA, M.F. 1976. Inventário florestal de um hectare de mata de terra-firme no $\mathrm{km} 30$ da estrada Manaus-Itacoatiara. Acta Amazonica, 6(1): 9-35.

RIBEIRO, M.N.G; SALATI, E; VTLLANOVA, N.A.; DEMÉTRIO, C.G.B. 1982. Radiaçāo solar disponivel em Manaus (AM) e sua relação com a duração do brilho solar. Acta Amazonica, $12(2): 346-399$

ROUSTEAU, A. 1983. 100 Plantules d'arbres de Guadeloupe: Aspects morphologiques écologiques. Thèse 3 éme cycle. Université Paris VI, Paris.

SILVA, M.F; GOLDMAN, G.H:; MAGALHÃES, F.M.M:: MOREIRA, F.W. 1988. Germinaçāo natural de 10 leguminosas arbóreas da Amazónia 1. Acta Amazônica, 18(1/2):9-26.
SILVA, M.F; CARREIRA, L.M.M.; TAVARES, A:S.; RIBEIRO, I.C.; JARDIM, M.A.G; LOBO, M.G.A.; OLIVEIRA, J. 1989. Leguminosas da Amázônia Brasileira Lista prévia. In: ANON (ed.) Anais do XXXIX Congresso Nacional de Botânica, 2(1): $193-237$

TOLEDO, F.F; MARCOS-FILHO, J. 1977. Manual das sementes - Tecnologia da Produção. Editora Agronômica Ceres, Sâo Paulo, 224p.

VARELA. V.P; BARBOSA, A.P. 1986/87. Conservação de sementes de cedrorana (Cedrelinga catenaeformis Ducke) Leguminosae. Acta Amazonica, 161 17():549-556.

VARELA, V. P.; AQUINO, P. A. N.; AZEVEDO, C. P. 1986/87. Tratamentos pré-germinativos em sementes de espécies florestais da Amazônia. III. faveira arara tucupi (Parkia decussata Ducke) Leguminosae. Acta Amazonica, 16/17():557-562

VASTANO JUNIOR, B; BARBOSA, A. P : GONCALVES, A. N. 1983. Tratamentos pré-germinativos de sementes de espécies florestais Amazônicas. I. Angelim pedra (Dinizia excelsa Ducke) Leguminosae Mimosoideae, Acta AmazOnica, 13(2):413-419. 